(C) 2019 IJHRMLP, Assam, India

\title{
Contraceptive knowledge, practice and acceptance among women seeking termination of pregnancy
}

\author{
Borthakur $S^{1}$, Sarma AK ${ }^{2}$, Bhattacharjee AK ${ }^{3}$, Borooah PC $C^{4}$, Rajashree $R^{5}$ \\ Received on June 10, 2016; editorial approval on August, 08, 2016
}

\begin{abstract}
Background: The widespread adoption of family planning in a society is an integral component of modern development. Objectives: The study was conducted to assess the contraceptive knowledge, practice and acceptance among women seeking termination of pregnancy at Guwahati Medical

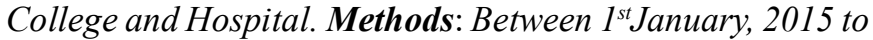
$31^{\text {st }}$ December 2015, 699 women who were put for Medical termination of pregnancy (MTP) by suction evacuation, after workup and investigation were taken up for the study in Guwahati Medical College and Hospital. They were interrogated on a structured questionnaire. After termination of pregnancy, the contraceptive method opted by the women was noted down. Results: Of the 699 women who came for voluntary termination of pregnancy, 594(84.98\%) did not use contraception earlier, though $(81.69 \%)$ women were aware of more than one method of contraception. The request for MTP was on grounds of family being completed (29.61\%), previous child was small (25.75\%), and financial instability (22.32\%). Post abortion $32.47 \%$ accepted concurrent sterilisation and $26.04 \%$ had an IUCD inserted immediately. Conclusion: Though the awareness about various contraceptive methods was high, yet practice of contraception was low. Acceptability was high once the women underwent termination of pregnancy.
\end{abstract}

Keywords: Intra uterine contraceptive device; oral contraceptive pill

\section{INTRODUCTION}

The population explosion is affecting the whole world,particularly detrimental to the infrastructure of developing country like India. There is a definite need of giving utmost importance to regular contraception and emergency contraception. ${ }^{1}$ MTP should be offered in case of unwanted pregnancy. With the use of regular and emergency contraception the need for MTP will be much reduced. ${ }^{2}$ Our country is the second most populous in the world having a rapidly growing population and contraceptive practice is the only answer.

Objectives: The study was conducted to assess the contraceptive knowledge, practice and acceptance among women seeking termination of pregnancy.

\section{MATERIALS AND METHODS}

In this study conducted in the Department of Obstetrics and Gynaecology, Guwahati Medical College and Hospital, from 1st January, 2015 to $31^{\text {st }}$ December 2015. A total of 699 women were put for termination of pregnancy by suction evacuation, after examination, workup and investigations. These women were questioned based on a standared questionair. MTP was done and the method opted or taken concurrently was noted down. Those who came with incomplete abortion or underwent MTP for obstetric reason like missed abortion, molar pregnancy, congenital anomalies or came with spontaneous abortion were excluded from the study as they might not be willing to use contraception because they would want a pregnancy. Cases of medical abortion

\section{Address for correspondence:}

${ }^{1}$ Post Partum officer of Obstetrics and Gynaecology

Gauhati Medical College \& Hospital

${ }^{2}$ Associate Professor of Physiology (Corresponding author)

Tezpur Medical College, Tezpur, Assam, India

Email: anupal.sharma@rediffmail.com

Mobile: +919864051793

${ }^{3} \mathrm{Head}$ of Obstetrics \& Gynaecology, ${ }^{4} \mathrm{RMNCH}+\mathrm{A}$

Counselor, ${ }^{5} \mathrm{RMNCH}+\mathrm{A}$ Counselor, Gauhati Medical

College \& Hospital, Guwahati, Assam, India 
using mifepristone and misoprostol were excluded as they were mostly lost to follow up and some ended in incomplete abortion for which evacuation had to be performed at a later date.

\section{RESULTS}

In this study $42.49 \%$ belonged to the age group of $26-30$

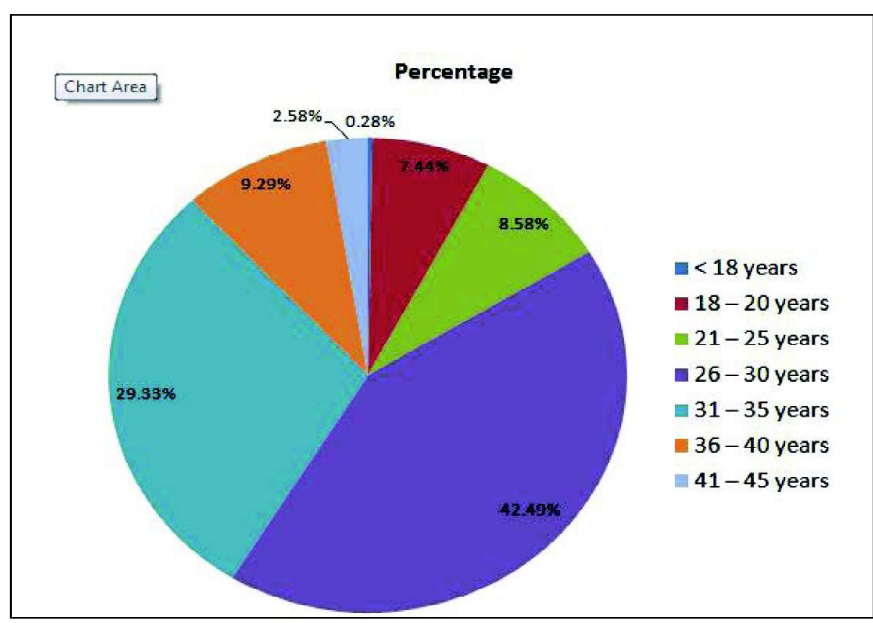

Figure 1 Showing Age wise distribution of clients seeking MTP

years of the 699 women, $18.31 \%$ were not aware of any contraceptive methods. But the majority knew about more than one method of contraception. Though awareness level was high, only $15.02 \%$ practiced some form of contraception previously. This is depicted in Table 1 below.

Table 1 Awareness of contraceptive methods (Number overlaps as some are aware of more than one method)

\begin{tabular}{|l|l|l|}
\hline Method & Number & Percentage \\
\hline Female sterilization & 566 & $81 \%$ \\
\hline Condom & 450 & $64.38 \%$ \\
\hline OCP & 426 & $60.94 \%$ \\
\hline IUCD & 358 & $51.22 \%$ \\
\hline Emergency contraception & 200 & $28.61 \%$ \\
\hline Natural methods & 98 & $14.02 \%$ \\
\hline Male sterilization & 60 & $8.58 \%$ \\
\hline Injectables & 51 & $7.30 \%$ \\
\hline Not aware & 128 & 18.31 \\
\hline
\end{tabular}

Most of the women came to know about contraception from family and friends $(46.35 \%)$, Doctors/nurse/paramedics (43.78\%), television (36.62\%) and School and College education (32.90\%). Majority of termination of pregnancy were done at the gestational age of $<12$ weeks $(97.57 \%)$. This is depicted in Table 2 below.
Table 2 Source of knowledge of contraception (Number exceeds as source overlaps)

\begin{tabular}{|l|l|l|}
\hline Source & Number & Percentage \\
\hline Family members/friends & 324 & $46.35 \%$ \\
\hline Radio & 126 & $18.02 \%$ \\
\hline Television & 256 & $36.62 \%$ \\
\hline News paper/magazine & 120 & $17.17 \%$ \\
\hline Doctors/nurse/paramedics & 306 & $43.78 \%$ \\
\hline School and college education & 230 & $32.90 \%$ \\
\hline No knowledge & 128 & $18.31 \%$ \\
\hline
\end{tabular}

$29.61 \%$ women did not want a child as their family was complete followed by $25.75 \%$ wanted termination as their previous child was small. On questioning whether they regretted that they had to terminate pregnancy, 86.84 had no regret. Out of 699 women who underwent MTP, concurrent sterilization was done in $227(32.4 \%)$ cases and IUCD was given in $182(26.04 \%)$ cases. This is depicted in Table 3 below.

Table 3 Reason given by clients for termination of the present pregnancy

\begin{tabular}{|l|l|l|}
\hline Reason & Number & Percentage \\
\hline Previous child was small & 180 & $25.75 \%$ \\
\hline Family complete & 207 & $29.61 \%$ \\
\hline Pursuing studies & 82 & $11.73 \%$ \\
\hline Financial instability & 156 & $22.32 \%$ \\
\hline Not married & 62 & $8.87 \%$ \\
\hline Contraceptive failure & 10 & $1.43 \%$ \\
\hline Widow (Social cause) & 2 & 0.29 \\
\hline
\end{tabular}

Of the remaining 290 cases majority promised to start oral contraceptive pills. This is depicted in Table 4 below.

Table 4 Choice of method for future use by women who did not accept immediate contraception

\begin{tabular}{|l|l|}
\hline Method & Number(n=290) \\
\hline OCP & 125 \\
\hline Condom & 55 \\
\hline Interval IUCD & 50 \\
\hline Female sterilization & 20 \\
\hline Male sterilization & 2 \\
\hline Injectable & 2 \\
\hline Undecided & 36 \\
\hline
\end{tabular}




\section{DISCUSSION}

In our study $51 \%$ coming for voluntary termination were in the age group of 21-30 years which is comparable to the study by Parvati V, Bhat et $\mathrm{al}^{3}(70 \%)$, Sonali Gaikwad et $\mathrm{al}^{4}$ (37\%) and Sanjay R Quraishi et $\mathrm{al}^{5}(75.24 \%)$. In this study the percentage of illiterate were only $10.73 \%$ which is comparable to Parvati V, Bhat et al. ${ }^{3}$ Education, religion and place of residence had no influence in the percentage of women seeking abortion.

In this study $43 \%$ of MTP seekers were Para-1, in contrast to Parvati V, Bhat et $\mathrm{al}^{3}$ where $80.4 \%$ women were Para- 1 .

Awareness level about different contraceptive methods was very high in our study. Only $18.31 \%$ were not aware of any method of contraception. Most of the women knew about more than one method. Highest awareness was about female sterilization (81\%), which is comparable to the study by Srivastava Reena et $\mathrm{al}^{6}(82.1 \%)$ and Sonali Gaikwad et $\mathrm{al}^{4}$ $(82 \%)$. Though these women were aware of various contraceptive methods, $84.98 \%$ were not practicing any method of contraception which is comparable to the study by Parvati V, Bhat et $\mathrm{al}^{3}(76.3 \%)$ and Srivastava Reena et $\mathrm{al}^{6}$ (55.2\%). In the study by Suneeta Mittal et $\mathrm{al}^{7}$ only $39.1 \%$ were not using contraceptive methods earlier. Most of the termination done were $<12$ weeks $(97.57 \%)$ in our study comparable to ParvatiV, Bhat et $\mathrm{al}^{3}(97.9 \%)$. In our study the main reason given for seeking abortion was because the family was complete $(29.61 \%)$, which is comparable to the study by Sanjay R Quraishi et $\mathrm{al}^{5}(31.25 \%)$. The second leading cause for seeking termination of pregnancy was that the first child was very small $(25.75 \%)$. Financial instability and marital status were two other independent factors determining the outcome of pregnancy in our study. Unfortunately $86.84 \%$ did not have any regrets about the termination of pregnancy which is comparable to the study by Parvati V Bhatet $\mathrm{al}^{3}$ (94.8\%).

After termination of pregnancy, $32.47 \%$ had concurrent sterilization done and $26.04 \%$ had an IUCD inserted immediately. This is comparable to the study by Mukhopadhyay et $\mathrm{al}^{8}$ on fertility regulation at Kolkata, where $35.8 \%$ accepted Copper $\mathrm{T}$ and $30 \%$ accepted permanent sterilization after MTP as a mode of contraception. The rest of the women decided to opt for a method of contraception at a later date. Even after counseling 36 women $(5 \%)$ who underwent MTP remained undecided whether to opt for a contraceptive method or not.

There is lack of awareness amongst many women about the availability of regular contraception and emergency contraception makes them more prone to unintended pregnancy and its complications. ${ }^{9,10}$

Among the family planning seekers, the majority of women opted for IUCDs or permanent tubal sterilization which continues to be popular in India. ${ }^{11-14}$

\section{CONCLUSION}

The present study highlights the fact that though awareness about contraceptive methods was high, the use of contraceptive methods was very low. This is the main reason for a high fertility rate. Hence we recommend spread of correct knowledge about the different contraceptive methods and motivation for contraceptive use by doctors and health workers. The media and non-government organizations (NGO) can play a role to improve the female healthcare in the larger perspective. Another important factor is regular availability of contraceptives and adequate health care services at the peripheral level.

Ethical clearance: Taken.

Source of funding: Nil.

Source of conflict: None declared.

Contribution of Authors: We declare that this work was done by the authors named in this article and all liabilities pertaining to claims relating to the content of this article will be borne by the authors.

\section{REFERENCES}

1. Trussell J. Contraceptive efficacy. In: Hatcher RA, Trussell J, Stewart F editors. Contraceptive technology. $17^{\text {th }}$ ed. New York (NY): Ardent Media; 1998. p. 419.

2. Kenny L, Luesley DM, Baker PN. Contraception, sterilization and termination of pregnancy in obstetrics and gynaecology - an evidence-based text for MRCOG. $1^{\text {st }}$ ed. London: Arnold; 2004. p. 514-23.

3. Parvati V Bhat, Aahwini Prabhu, Pratap Kumar, Sree kumaran. Contraceptive knowledge, practice and acceptance among women seeking termination of pregnancy at a secondary level hospital in southern Karnataka. Health and Population-Perspective and Issues 2008;31(3):157- 62 .

4. Gaikwad S, Siroh S, Rokade R. A study on Contraceptive knowledge, attitude and practice (KAP) among women attending family planning clinic of a private hospital of western INDIA. Intl $\mathrm{J}$ of recent trends in Science and Technology 2015;13(3):585-8.

5. Sanjay R Quraishi, Vivek B Waghachavare, Alka D Gore, Girish B Dhumale. Evaluation of indications and adoptions of contraceptive practices in MTP seekers from Sangli-MirajKupwad corporation area Maharashtra. Innovative J of Medical and Health Science 2014 March-April;4(2):75-8.

6. Srivastava R, Srivastava DK, Jina R, Srivastava K, Sarma N, Saha. Contraceptive knowledge, attitude and practice (KAP) Servey. $\mathrm{J}$ of Obstetrics and Gynaecology of India 2005;55(6):546-50.

7. Mittal S, Bahadur A, Sharma JB. Survey of the attitude to, knowledge and practice of contraception and medical abortion in women attending a family planning clinic. J Turkish - German Gynecol Assoc 2008;9(1):29-34.

8. Mukhopadhyay A Kumar, Ghosh Anuradha, Goswami Sebanti, Adhikari Sudhir. Fertility regulation -5 years study. J of Obstetrics \& Gynaecology of India 2008 Sep-oct;58(5):421-4.

9. Royal College of Obstetricians and Gynecologists Care of women requesting induced abortions. Evidence based clinical guidelines no.7.RCOG Press, London, 2004.

10. Bongaarts J. The KAP Gap and unmet need for contraception. Population and Development Review 1991;17:293-313.

11. Smith BH, Guney EM, Aboulela L, Templeton A. Emergency contraception: a survey of womens knowledge and attitudes. $\mathrm{Br}$ J Obstet Gynaecol 1996 Nov;103(11):1109-16.

12. Sharma JB, Malhotra M, Joshi D, Arora R. Survey of the patient's views on awareness, information, choices and care during labor in a teaching hospital. J Obstet Gynecol Ind 2003 May/ June:53(3):252-6.

13. Sharma JB, Sharma K, Sarin V. A study of maternal awareness and participation during cesarean section. J Obstet Gynecol Ind 2001:51(1):37-9.

14. Sharma JB, Newman MR, Boutchier JE. A national audit in breech deliveries in the United Kingdom. Int J Gynecol Obstet 1997;5:103-8. 